\title{
Research On Design and Application of Mobile Learning Platform Based On Cloud Computing
}

\author{
Nie Huiyu ${ }^{1, a}$ \\ ${ }^{1}$ Baicheng Normal College, Media Institute,Baicheng ,Jilin \\ a Bcnhy@sohu.com
}

Keywords: Cloud computing; Mobile learning; Learning system

\begin{abstract}
With the wide application of cloud computing and mobile technology, there has been a Innovative modes of learning, m-learning.Based on the analysis of status quo of mobile learning And cloud computing support based on mobile learning, set up a mobile learning platform, cloud computing,Mobile learning system is designed.
\end{abstract}

\section{The definition and characteristic of cloud computing and mobile learning}

The definition of cloud computing :Cloud computing is a kind of super computing model based on the Internet, it is stored in Computer (such as: personal computers, mobile phones and other devices) in a large amount of data and processing Implement resources together to work together.

Cloud computing support for mobile learning has the following features: according to the actual needs of learners, for messages, such as data points together Enjoy; no damaged data preserved, reduced set of learners and configuration requirements; put learners in the core position; Users learn form of defect was repaired .

The definition of mobile learning :Mobile learning is to use wireless communication technology, wireless communications equipment for teaching, etc Education information, information and serve education. The characteristics of mobile learning has the following features: convenience. Learners at any time access to mobile communication devices (such as mobile phone, Learning device, etc.); learning can have a variety of places or field. The user can, in the building What is like to study; fragmented knowledge. Learners influenced by external environment factors, lead to Learning knowledge content is relatively fragmented.

\section{The function of the mobile learning platform design based on cloud computing}

For now, in the near future, mobile learning is learners learn and raw, An integral part of living. And the cloud for mobile learning into a new life. Force. In the design of mobile learning platform system, the need to consider the following several major functional modules:

User registration and login. Users with ID to register first, and then in.Enter your user name and password learning platform. After the success of the platform login, the user is.Become a legitimate users. After registration, users need to input the correct use at the same time Username and password can be immediately successful login, enter the main interface, the user in the system

Is not subject to any restrictions, according to their own needs, to the inside of the information and data to read.

Provide online learning resources. Build or design new learning with the database.Anywhere is ok, such not only can fill the lack of learning database, can also be used.The diversity of rich learning database, still can let more people enjoy abundant data Library. Rich database can make more different levels of people have more choices. In this paper, Design under the cloud computing architecture of mobile system is colleges and universities, as a network,Network teaching, homework online submission, remote teaching, the teachers and students interact, online to submit a job. A new model and examination, etc.). The current mobile learning system application is the most common .Accounting operations, which include the accountant continue education, for all kinds of account .According to the test content, such as for the work is busy and no time for face-to-face were provided the convenient. 
Online test link. This system to facilitate the online interactive learning,Specially developed a test in the system function. The students examination questions.Are belong to the individual port, its purpose is to prevent teachers out of the exam Topic, students only to obtain the correct user name and password at the same time, to be successful log in to the teacher individual servers, but only online for the whole process. students after permission is obtained during the test finish examination, and submit to complete online. Finally students see their test scores and online examination questions of the reference answer.

The interaction between learners communicate with each other, exchange. Learners use mobile communication Equipment (such as: mobile phone, tablet, etc.) for tencent QQ conversation, reading and writing papers, etc.Learning, in a variety of places or places users themselves to each other at any time Supply some information to each other. If you don't online learners, available mobile communications equipment (such as: mobile phone, tablet, etc.) of the information or data, etc. Users can also through the other way to communicate with each other and play.

\section{A typical example of cloud computing}

Cloud computing is represented the typical product Windows Live, it is mainly for create conditions for teaching scene, arouse the enthusiasm of learners and hobbies, it can let students cooperate with each other, mutual learning task, and can improve the students' organization and coordination force and students cooperate with the tacit understanding.

Typical products on behalf of the registered Windows Live :Learners want to use the product on behalf of Windows Live, the following steps: the first step is to register their own private accounts, namely the registered user name and password; It opens at the second step products main interface of Windows Live find registration dialog box; The third step, according to every item in the dialog box prompts according to the requirements of the complete and can be registered. At the same time is a must to successful login Windows Live products, using the correct username and password.

With the Windows Live with each other and common tasks:Students want to use the product on behalf of Windows Live under system based on cloud computing mobile learning, students have to do is to their own needs to be done in the right direction under the guidance of learning, and teachers should do is through leading, coordination, publish, overall arrangement and teaching related information or data, etc. Its purpose is to make students to consciously online, reasonably arrangement study plan. Windows Live products instead of the traditional face-to-face mode, gives students a variety of application services, through the web services platform can preview, read, or download the various needs of information (PPT, lesson plans, exam outline, etc.), can also be interaction between teachers and students, examination, online work, etc. Between teachers and students can also use online instant messaging (refers to is Windows Live Messenger) mutual discussion and communication way, so that once students have learning problems, teachers can be directly read online, modify, and guidance, students under this way of learning will become more meaningful.

Remote synchronization :All kinds of data in Microsoft office software package is simple and easy to be stored or transmitted to the online platform, students are not subject to any restrictions in any time or any place or places continue to own nothing is finished. At the same time, if lets the student online storage of processed materials, so that students will continue to get have the updated information.

Published data:Students' learning data (generally refers to assigned projects, courseware notes or teacher lesson plans, etc.) can be uploaded in the Windows Live products. After transfer of learning materials if you have others demand, as long as in the link to the right IP or download data can be input the correct url. It is not only resource sharing, and it can make up for the inadequacy of "database".

Until now, the cloud of mobile learning is in development period, but "cloud computing" in each aspect shows it has incomparable advantages and benefits, especially based on cloud computer mobile learning. This article has carried on the cloud computing mobile learning platform design, combined with the new technology and new idea, can maximum limit satisfy the learners at any 
time, any place without any freely for online learning. For now, the "cloud computing" into the mobile platform and there are many small problems, for the rapid development of information network technology, "cloud computing" is stable in all walks of life development. Especially in the development of mobile learning under the "cloud computing" appear alive, and can have a great impact on the education technology.

\section{References}

[1] Degree paper Based on virtual instrument data acquisition process of researching 2006

[2] Huang jiarong Labview-based virtual design of electronic test systems Journal of Southwest University for Nationalities May,2006.

[3] National Instruments Labview8.6 Upgrrade Notes,Aug.2008.

[4] Pan yongXiong etc. Practical Guide to Electronic Circuit CAD Xian University Press, Mar,2005.

[5] Liugang Labview 8.20 Chinese version of the programming and application Electronics Industry Press, Jan,2008. 